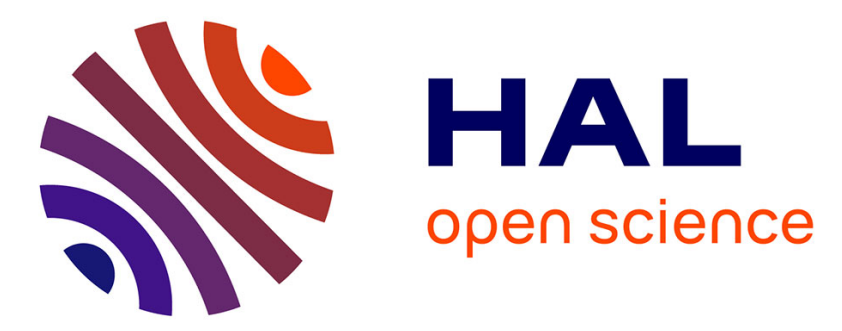

\title{
STOCK PRICES AND MONETARY POLICY SHOCKS: A GENERAL EQUILIBRIUM APPROACH
}

Edouard Challe, Chryssi Giannitsarou

\section{To cite this version:}

Edouard Challe, Chryssi Giannitsarou. STOCK PRICES AND MONETARY POLICY SHOCKS: A GENERAL EQUILIBRIUM APPROACH. 2012. hal-00719956v2

\section{HAL Id: hal-00719956 \\ https://hal.science/hal-00719956v2}

Preprint submitted on 7 Sep 2012

HAL is a multi-disciplinary open access archive for the deposit and dissemination of scientific research documents, whether they are published or not. The documents may come from teaching and research institutions in France or abroad, or from public or private research centers.
L'archive ouverte pluridisciplinaire HAL, est destinée au dépôt et à la diffusion de documents scientifiques de niveau recherche, publiés ou non, émanant des établissements d'enseignement et de recherche français ou étrangers, des laboratoires publics ou privés. 


\section{ECOLE POLYTECHNIQUE}

CENTRE NATIONAL DE LA RECHERCHE SCIENTIFIQUE

\section{STOCK PRICES AND MONETARY POLICY SHOCKS:} A GENERAL EQUILIBRIUM APPROACH

Edouard CHALLE

Chryssi GIANNITSAROU

September, 2012

Cahier $n^{\circ} 2012-20$

\section{DEPARTEMENT D'ECONOMIE}

Route de Saclay

91128 PALAISEAU CEDEX

(33) 169333033

http://www.enseignement.polytechnique.fr/economie/

mailto:chantal.poujouly@polytechnique.edu 


\title{
STOCK PRICES AND MONETARY POLICY SHOCKS: A GENERAL EQUILIBRIUM APPROACH*
}

\author{
Edouard Challe ${ }^{\dagger} \quad$ Chryssi Giannitsarou ${ }^{\ddagger}$
}

September 2, 2012

\begin{abstract}
Recent empirical literature documents that unexpected changes in the nominal interest rates have a significant effect on real stock prices: a 25-basis point increase in the nominal interest rate is associated with an immediate decrease in broad real stock indices that may range from 0.6 to 2.2 percent, followed by a gradual decay as real stock prices revert towards their long-run expected value. In this paper, we assess the ability of a general equilibrium New Keynesian asset-pricing model to account for these facts. The model we consider is a production economy with elastic labor supply, staggered price and wage setting, as well as time-varying risk aversion through habit formation. We find that the model predicts a stock market response to policy shocks that matches empirical estimates, both qualitatively and quantitatively. Our findings are robust to a range of variations and parameterizations of the model.
\end{abstract}

KEYwords: Monetary policy; Asset prices; New Keynesian general equilibrium model JEL Classification: E31, E52, G12

\footnotetext{
${ }^{*}$ We are grateful to Alexis Anagnostopoulos, Harjoat Bhamra, Eva Carceles-Poveda, Harris Dellas, Wouter den Haan, Mike Haliassos, Urban Jermann, Christian Julliard and Anastasia Zervou for helpful discussions and comments. We also thank seminar and conference participants at the 7th Conference on Research on Economic Theory \& Econometrics, EEA-ESEM 2008, Warwick University, Paris I Sorbonne, Paris School of Economics, Ecole Polytechnique and University of Edinburgh. Edouard Challe acknowledges the financial support of the chair FDIR.

${ }^{\dagger}$ Ecole Polytechnique, CREST and Banque de France. Email: edouard.challe@polytechnique.edu

${ }^{\ddagger}$ Faculty of Economics, University of Cambridge, and CEPR. E-mail: cg349@cam.ac.uk.
} 


\section{INTRODUCTION}

The reaction of the stock market to monetary policy shocks has been the subject of much empirical research in recent years. In particular, this literature documents that an unexpected change in the nominal interest rates has significant and persistent effects on real stock prices. Papers focusing on the instant stock market response to such a shock report that a 25-basis points increase in the Fed funds rate is associated with an immediate decrease in broad US stock indices that ranges from 0.5 to 2.3 percent, depending on the sample and estimation method being used (e.g., Craine and Martin, 2004; Rigobon and Sack, 2004, Bernanke and Kuttner, 2005; Bjørnland and Leitemo, 2009). Moreover, various authors document the dynamic effects of policy shocks and report a gradual mean reversion of real stock prices and returns following the shock (e.g., Lastrapes, 1998; Rapach, 2001; Neri, 2004).

Such estimated reactions of the stock market to policy shocks are of potential interest for researchers in macro-finance for two reasons. First, they convey important information on the transmission channels of monetary policy, since policy shocks affect financial variables immediately, while they only have delayed effects on macroeconomic variables. Second, these estimates provide raw stylized facts against which the quantitative predictions of alternative theoretical frameworks can be evaluated. In this paper, we assess the ability (and potential limitations) of a simple New Keynesian asset-pricing model to account for such empirical regularities. In particular, we address the impact and dynamic adjustment of the stock market following a nominal interest rate shock within a quantitative general equilibrium framework that makes the necessary assumptions, but no more, to account for the evidence that we have just summarized. The model we consider is a standard production economy with elastic labor supply, with three additional features, namely staggered prices, staggered wages and time-varying risk aversion through habit formation. The first two features are important for generating reasonable macroeconomic implications, while the last one is an important ingredient for obtaining some basic asset pricing facts. We discuss each of these three assumptions in turn.

The first required property of the model is that money should be non-neutral for monetary policy shocks to affect real macroeconomic and asset pricing variables. We generate this feature through the common assumption that goods prices are set in a staggered fashion by monopolistically competitive firms. Various versions of the New Keynesian framework that we are using have already been extensively used to account for the documented effects of policy shocks on macroeconomic variables (e.g., Amato and Laubach, 2003; Woodford, 2003; Christiano et al., 2005). While the sticky-price framework has occasionally been used to study some asset pricing issues such as the term structure of interest rates, its ability to account for the effects of monetary policy shocks on the stock market has not yet been fully assessed. This is rather surprising, given that the asset pricing version of this model seems to be the most natural framework within which the quantitative impact of nominal interest rate shocks on the stock market can fruitfully be examined.

Nevertheless, the basic sticky price model suffers from one unfortunate implication, which relates to its predicted labour market adjustments following a monetary policy shock. For example, after a contractionary shock, e.g. an increase in the nominal interest rate set by the Central Bank, firms' labour demand falls. If nominal wages are fully flexible, this translates into a sharp fall in the real wage, which in turn lowers the production cost of firms and ultimately raises the firms' profits paid out as dividends. Both implications are clearly counterfactual, since profits and dividends 
are procyclical, while the real wage is only mildly procyclical (see Bernanke and Kuttner, 2005; Christiano et al., 2005). The simplest explanation for the mild documented drop in the real wage and implied increase in profits and dividends following the shock is that nominal wages are also sticky and set in a staggered fashion. In this paper, we follow much of the literature in assuming staggered wage setting by households, modelled as monopolistic suppliers of labour services who face specific constraints on nominal wage adjustment (e.g., Christiano et al., 2005; Erceg et al., 2000).

Finally, both the evidence on stock market volatility (e.g. Campbell and Shiller, 1988, Campbell, 2003) and that on the specific impact of monetary policy shock (e.g. Bernanke and Kuttner, 2005 ) point to the fact that expected excess returns are time-varying and that such variations contribute to the volatility of real stock prices and ex post excess returns, just as dividends and real interest rates do. We therefore introduce an active role for time-varying expected excess returns in the stock market reaction to policy shocks by assuming that households form consumption habits, with a specification for habit formation that generates time-variations in households' risk aversion.

As it turns out, these three assumptions (staggered price setting, staggered wage setting and time-varying risk aversion) are sufficient to explain, both qualitatively and quantitatively, the response of real stock prices to a monetary policy shock documented by empirical studies. Thus, while adding other realistic features to our baseline model (such as the introduction of lags in information processing as in Amato and Laubach, 2003, or capital formation with capital adjustment costs as in Christiano et al., 2005) would probably refine our results, they do not a priori appear as necessary to account for the empirical evidence summarized above. We find that, using a parameterization that is in line with the business cycle facts, the predicted impact on stock price and return multipliers are well inside the range of available empirical estimates; moreover these numbers are robust to a variety of parameterizations and simple variations of the model. Our results suggest that the baseline New Keynesian model provides a natural general equilibrium explanation for the observed stock market reaction to monetary policy shocks.

Our contribution here is also methodological: we propose a hybrid of the log-linear log-normal approach that allows us to express real stock prices as a linear function of future dividends, real interest rates and time-varying risk aversion. As is well known, standard log-linearizations of asset pricing models around the deterministic steady state eliminate second order terms that are important when analyzing equity premia and asset returns; second order approximations or the usual log-linear log-normal approach bring back second order terms but imply constant risk aversion and excess returns, which is against the empirical evidence. ${ }^{1}$ We could resort to a third order approximation that preserves time variation in risk aversion and excess returns (as for example in Rudebusch and Swanson, 2008), however the potential non-linearities involved would make it very hard to isolate the contribution of each of these three channels for the transmission of monetary policy shocks to real stock prices. By assuming log-normality and working out a firstorder approximation of the current period multiplier around consumption in the previous period, we are able to maintain second order terms, and at the same time incorporate and track timevariations in risk aversion.

Our work relates to various strands of the literature. We have already mentioned the empirical

\footnotetext{
${ }^{1}$ Amisano and Tristani (2011) generate time varying risk premia with a second order approximation of a DSGE model, by allowing for exogenous stochastic regime shifts.
} 
papers on which our quantitative investigation is based (more details are provided in section 2). We have also referred to some contributions that study empirically the effect of monetary policy shocks on macroeconomic variables; an extensive survey of this work can be found in Christiano et al. (1999). Of course, there is also a long tradition in assessing the asset pricing implications of dynamic macroeconomic models, particularly within the Real Business Cycle tradition (see, for example, Jermann, 1998; Boldrin et al., 2001; Lettau, 2003). Within the New Keynesian tradition, Blanchard (1981) and Svensson (1986) provide early theoretical analyses of the stock market response to a monetary shock using rational expectations models with sticky goods prices and flexible asset prices. Some papers have studied the implications of sticky prices and non-neutral monetary policy for the shape and business cycle properties of the yield curve (e.g. Rudebusch and Swanson, 2008; Rudebusch and Wu, 2008; Doh, 2009; Bekaert, Cho and Moreno, 2010; Amisano and Tristani, 2011). Some more recent theoretical contributions that broadly analyze positive questions regarding asset prices in New Keynesian settings include Milani (2008), Li and Palomino (2009), Wei (2009), De Paoli, Scott and Weeken (2010), Castelnuovo and Nisticò (2010), Nisticò (2012). The major difference between our paper and these is that we provide an analytical decomposition of the effects of monetary shocks on real stock prices into three distinct channels of transmission. Moreover, Bhamra, Fisher and Kuehn (2011) study the implications of nominal rigidities in the value of firms debt for the way corporate bond spreads respond to monetary policy shocks. Finally, to the extent in which nominal interest rate shocks can be broadly viewed as generating uncertainty about monetary policy, our paper contributes to the literature of the effects of uncertainty about government policies on the stock market; for example see Sialm (2006) and Pastor and Veronesi (2012).

The rest of the paper is organized as follows. Section 2 presents the empirical findings in more detail. Section 3 introduces the macro block of our basic New Keynesian model. Section 4 derives in detail the asset pricing block of the model. In section 5 we explain and then implement the solution procedure we use to compute and decompose the stock-price multiplier. Section 6 presents our baseline results and performs a number of sensitivity and accuracy tests. In section 7 we summarize our findings and provide some concluding remarks.

\section{EMPiRical EVIDENCE}

Table 1 reports the main pieces of recent evidence relating to the impact effects of unanticipated monetary policy shocks, in the U.S. and some European countries. For each study we refer to, we only report the baseline estimates of the reaction of broad stock market indices, leaving aside results based on robustness checks, less representative indices (e.g., the NASDAQ), or industry-specific indices. The figures reported in the last column give the reaction of the stock market value or index return following a one percentage point surprise increase in the short term nominal interest rate (the two measures are nearly identical since price changes govern ex post returns changes at high frequency). The exact value of the multiplier may vary across specifications, depending on the particular empirical methodology being implemented or the underlying data being used (e.g. the exact stock market index whose variation is measured, or the specific futures rate used to extract markets expectations and isolate the surprise component of policy shocks). However, despite these variations the overall picture that emerges from these numbers is consistent across papers, with a monetary policy shock having a significant impact on the stock market and estimated multipliers ranging from $-2.55 \%$ to $-9.00 \%$ for the US and $2.02 \%$ to $9.40 \%$ for European countries. 


\begin{tabular}{|lllll|}
\hline & Country & Index & Sample & Multiplier \\
\hline \hline Rigobon and Sack (2004) & U.S. & DJIA & $1994-2001$ & -4.85 to -5.16 \\
& U.S. & SP500 & $1994-2001$ & -5.78 to -6.81 \\
Craine and Martin (2004) & U.S. & NYSE & $1988-2001$ & -2.80 to -4.92 \\
Ehrmann and Fratzscher (2004) & U.S. & SP500 & $1994-2003$ & -5.50 \\
Bernanke and Kuttner (2005) & U.S. & NYSE & $1989-2002$ & -2.55 to -4.68 \\
Gürkaynak et al. (2005) & U.S. & SP500 & $1990-2004$ & -3.96 to -4.53 \\
Basistha and Kurov (2008) & U.S. & SP500 & $1990-2004$ & -4.23 to -5.51 \\
Bjørnland and Leitemo (2009) & U.S. & SP500 & $1982-2002$ & -7.00 to -9.00 \\
Bohl et al. (2008) & Euro Area & Eurostoxx50 & $1999-2007$ & -7.66 to -9.40 \\
& Germany & DAX30 & $1999-2007$ & -6.99 to -7.78 \\
& France & CAC40 & $1999-2007$ & -6.34 to -7.07 \\
& Spain & IBEX35 & $1999-2007$ & -5.99 to -6.36 \\
& Italy & MIB30 & $1999-2007$ & -3.49 to -4.32 \\
Kholodilin et al. (2009) & Euro Area & Datastream & $1999-2008$ & -2.02 to -4.34 \\
\hline
\end{tabular}

Table 1: Stock prices or ex post returns responses to a surprise increases in the policy interest rate. Note: The multipliers are normalized semi-elasticities summarizing the proportional change in prices or returns following a 1 percentage point increase in the level of the nominal interest rate.

Apart from their immediate impact on real stock market indices, monetary policy shocks are also shown to have different and persistent effects on financial asset prices. For example, Patelis (1997) shows that monetary policy indicators such as the Fed funds rate or the term spread help forecast future excess returns. Other papers have used identified VARs to recover the dynamic adjustment of real stock prices to policy shocks. For example, Lastrapes (1998) documents that the reversion of real stock prices following a money supply shock is of comparable speed as that of macroeconomic variables in a number of OECD countries. In related work, Rapach (2001) and Bjørnland and Leitemo (2009) extend and confirm this observation of a gradual decay of real stock prices following a monetary policy shock. Such impulse-response patterns suggest that stockprice variables share much of the dynamic properties of other economic aggregates (at least at the quarterly frequency that we are considering here) and that they can consequently be modelled using similar macroeconomic models.

\section{A Basic New Keynesian Model}

We now introduce our baseline macroeconomic model, the asset-pricing implications of which we derive in Section 4. The macroeconomic block of the model is essentially a stripped-down version of the New Keynesian framework, based on Amato and Laubach (2003) and Woodford (2003). Time is discrete. The economy is populated by monopolistically competitive firms and households that adjust nominal prices and wages in a staggered fashion and where households form consumption habits. There is also a monetary authority that sets the nominal interest rates according to a Taylor rule.

There is a continuum of households of measure one, indexed by $\iota \in[0,1]$ and a continuum of firms of measure one, indexed by $h \in[0,1]$. Each household is the monopolistic supplier of a specific variety of labour service demanded by all firms and consumes all varieties of the consumption good, each of which is produced by a monopolistic firm. Individual varieties of the consumption good and labour service contribute towards households' instantaneous utility and firms' production according to constant-elasticity-of-substition (CES) aggregators. We denote with $P_{t}$ and $W_{t}$ the 
conformable CES price and wage indices, with the cross partial elasticity of substitution between varieties of the consumption good and labour service being $\theta_{p}>1$ and $\theta_{w}>1$, respectively. We focus on the symmetric equilibrium with full consumption insurance, so that all households end up consuming the same quantity of the consumption aggregator, $C_{t}$. Finally, since there is no capital accumulation and hence no investment demand, we shall have $C_{t}=Y_{t}$.

All monopolistically competitive firms follow the production function $Y_{t}(h)=\exp \left(\hat{z}_{t}\right) N_{t}(h)$, where $Y_{t}(h)$ is the output of firm $h, N_{t}(h)$ is the use of the labour aggregator by firm $h$ and $\hat{z}_{t}$ is an aggregate productivity shock obeying the following $\mathrm{AR}(1)$ process:

$$
\hat{z}_{t}=\alpha \hat{z}_{t-1}+u_{t}, u_{t} \sim N\left(0, \sigma_{u}^{2}\right)
$$

Firms maximize the present value of the monopolistic profits that are paid out to their owners (i.e. the households) in the form of dividends. The real dividend paid out by firm $h$ at date $t$ is the receipts from selling one unit of good $h$ minus its production cost, i.e.

$$
D_{t}(h)=\left(P_{t}(h) Y_{t}(h)-W_{t} N_{t}(h)\right) / P_{t} .
$$

A firm $h$ sets the selling price of its variety, $P_{t}(h)$, taking as given aggregate demand $C_{t}$, the general price and wage levels $P_{t}$ and $W_{t}$, the production function, the demand curve for its own variety and the exogenous constraints on price setting it faces.

The price adjustment mechanism assumed here is similar to that in Christiano et al. (2005). Specifically, in each period there is an instantaneous probability $1-\psi_{p} \in(0,1)$ that a firm optimally resets the nominal price it charges. Non-optimized prices grow at the rate of last period's price inflation, which occurs with probability $\psi_{p}$. As shown by Woodford (2003), the dynamics of the price level can be first-order approximated by the following New Keynesian Phillips Curve:

$$
\pi_{t}=\left(\frac{1}{1+\beta}\right) \pi_{t-1}+\left(\frac{\beta}{1+\beta}\right) E_{t}\left(\pi_{t+1}\right)+\kappa_{p}\left(\hat{\omega}_{t}-\hat{z}_{t}\right),
$$

where $\pi_{t}$ denotes the level-deviation of the inflation rate $P_{t} / P_{t-1}-1$ from its steady state, $\hat{\omega}_{t}$ is the log-deviation of the real wage $W_{t} / P_{t}$ from its steady state, $\beta \in(0,1)$ is the subjective discount factor of the representative household and $\kappa_{p}=\left(1-\beta \psi_{p}\right)\left(1-\psi_{p}\right) / \psi_{p}$. In (3), current inflation increases with the real unit production cost $\hat{\omega}_{t}-\hat{z}_{t}$, because of the markup pricing rule followed by monopolistically competitive firms. It also depends on past inflation through the indexation of non-optimized prices, as well as on future inflation, since re-optimizing firms set the price that will best keep their own selling price in line with the future general price level. ${ }^{2}$

At date $t$, household $\iota$ maximizes lifetime expected utility

$$
E_{t} \sum_{s=0}^{\infty} \beta^{t+s}\left[u\left(C_{t+s}, H_{t+s}\right)-v\left(N_{t+s}(\iota)\right)\right],
$$

with the instantaneous utility function being given by:

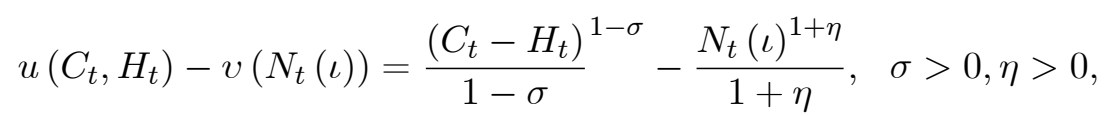

\footnotetext{
${ }^{2}$ Considering plausible forms of partial (rather than full) indexation hardly makes any difference for our quantitative results.
} 
where $C_{t}$ is the consumption aggregator, $N_{t}(\iota)$ is labour supply and $H_{t}$ is an external habit term that only depends on past aggregate consumption, i.e.

$$
H_{t}=b \bar{C}_{t-1}, b \in(0,1)
$$

where $\bar{C}_{t-1}$ is past aggregate consumption and $C_{t}=\bar{C}_{t}$ in equilibrium. The type of habit formation posited here is similar to that in Jermann (1998) and Boldrin et al. (2001), with the difference that the habit stock affects households' utility externally rather than internally.

We adopt the habit formation assumption essentially for two reasons. First, habits typically introduce sluggishness in the endogenous response of output to policy shocks. This is in line with empirical evidence (e.g. see Fuhrer, 2000) and is also relevant for asset prices through the way output fluctuations affect monopoly profits and thus the dividends paid out by firms. Second, specifying that habits enter as a difference (rather than as a ratio) in the households' utility function generates time-varying risk aversion; this will be an important ingredient for our analysis since it will naturally affect asset prices through changes in the expected excess returns at which dividends are discounted. The simplest form of habit formation that satisfies these properties is one with one lag only and habits being external to the representative household (i.e., the 'catchingup-with-the-Joneses' specification).

In every period, household $\iota$ chooses consumption, labour supply and asset holdings, taking goods and asset prices as given, so as to maximize expected lifetime utility. Households can transfer wealth across periods using both one-period nominal bonds and infinitely-lived shares, which are claims to the dividend flows paid out by firms. Nominal bonds are in zero net supply and the number of shares of each firm $h$ is normalized to one. Thanks to full consumption insurance, all households face the same following budget constraint:

$$
C_{t}+\frac{B_{t}}{P_{t}}+\int_{0}^{1} S_{t}(h) Q_{t}(h) d h=\frac{W_{t} N_{t}}{P_{t}}+\frac{I_{t-1} B_{t-1}}{P_{t}}+\int_{0}^{1} S_{t-1}(h)\left(Q_{t}(h)+D_{t}(h)\right) d h .
$$

In (6), $B_{t}$ and $S_{t}(h)$ denote the holdings of nominal bonds and shares of firm $h$ by the representative household at the end of period $t$, respectively. $I_{t-1}$ is the gross nominal interest rate on nominal bonds from date $t-1$ to date $t$, and $Q_{t}(h)$ and $D_{t}(h)$ are the real price of a share of firm $h$ and the dividend paid out by firm $h$, respectively, both expressed in terms of aggregate consumption units. The linearized bond Euler equation gives the following New Keynesian IS curve:

$$
\hat{y}_{t}=\left(\frac{b}{1+b}\right) \hat{y}_{t-1}+\left(\frac{1}{1+b}\right) E_{t}\left(\hat{y}_{t+1}\right)-\left(\frac{1-b}{\sigma(1+b)}\right) E_{t}\left(i_{t}-\pi_{t+1}\right),
$$

where $i_{t}$ is the level-deviation of the nominal interest rate from its steady state and $\hat{y}_{t}$ denotes the log-deviation of current output from its steady state value. Equation (7) summarizes the determinants of current aggregate demand, which is affected by the real interest rate through intertemporal substitution in consumption, future aggregate demand due to consumption smoothing and past aggregate demand due to habit formation.

Household $\iota$ has monopolistic market power over the supply of labour variety $\iota$ and sets the wage charged so as to maximize intertemporal utility taking as given his budget set, the general price and wage levels $P_{t}$ and $W_{t}$, the demand curve for labour variety $\iota$ and the exogenous constraints on nominal wage adjustment. The assumed wage adjustment mechanism is similar to that of prices: 
households optimally reset nominal wages with probability $1-\psi_{w} \in(0,1)$ and let nominal wages grow at the rate of last period's wage inflation with probability $\psi_{w}$. The aggregate wage dynamics is then first-order approximated by the following wage Phillips curve:

$$
\pi_{t}^{w}=\left(\frac{1}{1+\beta}\right) \pi_{t-1}^{w}+\left(\frac{\beta}{1+\beta}\right) E_{t}\left(\pi_{t+1}^{w}\right)+\kappa_{w}\left(\hat{s}_{t}-\hat{\omega}_{t}\right)
$$

where $\pi_{t}^{w}$ is the wage inflation rate, $\hat{s}_{t}$ is the log-deviation of the average marginal rate of substitution between leisure and consumption, $S_{t}=v^{\prime}\left(N_{t}\right) / u_{1}\left(C_{t}, H_{t}\right)$, from its steady state value and $\kappa_{w}=\left(1-\psi_{w}\right)\left(1-\beta \psi_{w}\right) /\left(1+\eta \theta_{w}\right) \psi_{w}$. With monopolistically competitive labour markets, optimizing households wish to keep their wage markup intact and thus raise the wage charged in response to an increase in the consumption-leisure MRS relative to the current real wage (see Erceg et al., 2001). Past wage inflation indexes non-optimized wages and thus affects current inflation. Finally, the attempt by optimizing households to keep their wage in line with the (anticipated) general wage level generates a feedback from future to current wage inflation. In equilibrium, we also have $H_{t}=b C_{t-1}$ and $N_{t}=Y_{t} / Z_{t}$, so that $\hat{s}_{t}$ is given by

$$
\hat{s}_{t}=\left(\frac{\sigma}{1-b}+\eta\right) \hat{y}_{t}-\left(\frac{b \sigma}{1-b}\right) \hat{y}_{t-1}-\eta \hat{z}_{t}
$$

The model is closed by specifying the way the central bank provides nominal anchor. In our baseline specification, we assume that the central bank reacts to current inflation and current output according to the following Taylor rule:

$$
i_{t}=\gamma i_{t-1}+(1-\gamma)\left(\rho_{\pi} \pi_{t}+\rho_{y} \hat{y}_{t}\right)+\varepsilon_{t},
$$

where $\rho_{\pi}$ and $\rho_{y}$ are positive reaction coefficients, $\gamma \in(0,1)$ reflects the degree of interest-rate smoothing by the central bank and $\varepsilon_{t} \sim N\left(0, \sigma_{\varepsilon}^{2}\right)$ is a nominal interest rate innovation, which by definition is unanticipated by private agents.

To summarize, the macro block of the model is described by the IS curve (7), the price and wage Phillips curves (3) and (8), the Taylor rule (10), the MRS equation (9), the aggregate productivity process (1), as well as the equation describing the evolution of the real wage, i.e.,

$$
\hat{\omega}_{t}=\hat{\omega}_{t-1}+\pi_{t}^{w}-\pi_{t}
$$

These equations are sufficient to fully describe all the macroeconomic variables of the model, without having to define and solve for outcomes in the financial markets. The reason for this is that our model has no first-order feedback from real stock prices to macroeconomic variables. Models that explicitly incorporate such feedbacks include, e.g., models with wealth effects (e.g., Castelnuovo and Nisticò, 2010) and models where stock prices enter the Taylor rule (e.g., Carlstrom and Fuerst, 2007). In those cases, Jermann's (1998) two-step procedure would not be applicable, and the macro and financial blocks of the model would have to be solved jointly irrespective of the type of solution method. 


\section{Financial Markets and Asset Pricing}

We now turn to the asset-pricing implications of the New Keynesian model just described. We are mostly interested in the impact and dynamic adjustments of real stock prices following a policy shock, rather than in the stochastic properties of real stock prices and returns per se. Therefore, we cannot simply recover unconditional first and second moments of those variables by subjecting our economy to a repeated sequence of policy and technology shocks. Rather, we must keep track of the households' information set in every period, since this information set is used by households to form conditional expectations for all future values of the variables relevant for the determination of real stock prices (i.e. dividends, real interest rates and expected excess returns).

The most tractable way of doing this is to use the households' rational expectations of those values that are based on the VAR representation of the log-linearized dynamics of the model. The log-linearized dynamic system remains valid as long as fluctuations around the deterministic steady state are sufficiently small. However, the standard way of applying this approach has a major drawback: by simply log-linearizing the dynamic system around its steady state, we lose second-order information that enters expected returns and may significantly affect the reaction of real stock prices to policy shocks. This point is particularly relevant here since our habit formation specification precisely allows for variations in equilibrium expected excess returns.

The approach we propose consists of combining these log-linear and nonlinear elements in the following way. As mentioned earlier, our starting point is the methodology proposed by Jermann (1998), which consists of first solving the model for the aggregate macro dynamics, then using this solution to infer the behavior of equilibrium real stock prices using a nonlinear version of the Euler equation for stocks. In this spirit, we consider a usual first-order log approximation of dividends and real interest rates around their steady states. Then, we combine the log-linear log-normal approach with a particular linear approximation of the stochastic discount factor that allows us to express expected excess returns as a linear function of the state vector and preserve some of the second order information relevant for the determination of asset prices. ${ }^{3}$ Finally, we use the VAR dynamics of the state vector to compute rational forecasts of dividends, real interest rates and expected excess returns, which can then be inserted into a log-linear present value formula to recover current equilibrium real stock prices. Each of these steps are described in detail in the following subsections.

4.1. Dividends and the risk-free rate. Under monopolistic competition and CES aggregators, firm $h$ faces the demand function $C_{t}(h)=\left(P_{t}(h) / P_{t}\right)^{-\theta_{p}} C_{t}$. Substituting the latter into (2) and using the fact that $N_{t}(h)=e^{-\hat{z}_{t}} Y_{t}(h)$, we may rewrite the dividend paid out by firm $h$ at

\footnotetext{
${ }^{3}$ The loglinear-lognormal approach is fairly standard in the macro-finance literature, first introduced in Hansen and Singleton (1983) and later used, among others, in Jermann (1998), Lettau and Uhlig (2000), Campbell (2003), Lettau (2003), Carceles-Poveda (2005), Carceles-Poveda and Giannitsarou (2008). Jermann (1998) and Lettau (2003) also suggest ways in which linear and nonlinear elements can jointly be used to derive closed-form solutions to general equilibrium asset-pricing models, as we do. However, these approaches cannot be directly applied here, for the following reasons. In Jermann (1998), perfect competition allows for identifying ex post asset returns with the marginal product of capital, which can then be directly extracted from the linearized macroeconomic block of the model; this is impossible here since we are pricing a stream of pure profits, so that we must go instead from prices (given by the present value formula) to ex post returns (which are a weighted sum of stock price growth and dividend growth). Lettau's (2003) approach, on the other hand, can only be used when expected excess returns are constant.
} 
date $t$ as:

$$
D_{t}(h)=\left(\frac{P_{t}(h)}{P_{t}}-e^{-\hat{z}_{t}} \frac{W_{t}}{P_{t}}\right)\left(\frac{P_{t}(h)}{P_{t}}\right)^{-\theta_{p}} Y_{t} .
$$

Log-linearizing this around the steady state yields the following

$$
\hat{d}_{t}(h)=\hat{y}_{t}+\left(1-\theta_{p}\right)\left(\hat{\omega}_{t}-\hat{z}_{t}\right) \equiv \hat{d}_{t} .
$$

Note that the relative prices of varieties $P_{t}(h) / P_{t}$, only have second-order effects on firms' profits and thus disappear from the linearized dividend equation (13). This property, i.e. that all firms approximately pay out the same dividend stream, together with the fact any dividend stream is valued using a single pricing kernel (thanks to full consumption insurance), will allow us later on to straightforwardly aggregate firms' share prices into a single broad stock market index.

Let us now turn to the determination of the real interest rate of this economy. In principle, the real interest rate on a risk-free one-period bond that pays out one unit of the consumption good can be decomposed into the contributions of the nominal bond rate, expected inflation and a correction term reflecting the negative compensation for not bearing the inflation risk associated with holding nominal one-period bonds. In this paper, however, we take a first-order approximation to this risk-free real interest rate and thus write its log-deviation from steady state as:

$$
\hat{r}_{t+1}^{f}=r_{t+1}^{f}+\ln \beta \approx i_{t}-E_{t}\left(\pi_{t+1}\right),
$$

where $r_{t+1}^{f}$ is the $\log$ risk-free rate and $r^{f}=-\ln \beta$ is its value at the deterministic steady state. Note that taking into account the second-order properties of the risk-free rate is straightforward but cumbersome and does not affect our quantitative results significantly.

4.2. Expected excess returns and the stochastic discount factor. We now analyse the equilibrium real stock returns and prices implied by our model. To this purpose, we start by characterising equilibrium log-excess returns taking the stochastic discount factor (SDF) as given, and then propose a approximate expression for the SDF that allows us to explicitly solve for stock returns and prices as a function of the underlying macroeconomic variables.

Expected excess returns. Let $\Lambda_{t} \equiv\left(C_{t}-H_{t}\right)^{-\sigma}$ denote the households' marginal utility of current consumption, with $H_{t}=b C_{t-1}$ in equilibrium, and $M_{t+1}=\beta \Lambda_{t+1} / \Lambda_{t}$ the implied (unique) stochastic discount factor (SDF) of this economy. From the households' objective and budget constraint, their optimal share holdings are summarized by the following Euler equations:

$$
E_{t}\left(M_{t+1} R_{t+1}^{e}(h)\right)=1,
$$

for all $h \in[0,1]$ and where

$$
R_{t+1}^{e}(h)=\left(Q_{t+1}(h)+D_{t+1}(h)\right) / Q_{t}(h)
$$

is the return on holding a share of firm $h$ from date $t$ to date $t+1$.

We now apply the usual log-normal framework to derive our approximate asset pricing equations. More specifically, we conjecture that the SDF and ex post returns are jointly conditionally log-normally distributed, and then verify later on (Section 5) that this conjecture is true in 
equilibrium, under our approximated Euler equation for stocks. ${ }^{4}$ Under the joint log-normality assumption, (15) may be written as follows:

$$
E_{t}\left(m_{t+1}\right)+E_{t}\left(r_{t+1}^{e}(h)\right)+\frac{1}{2}\left(\sigma_{h}^{2}+\sigma_{m, t}^{2}+2 \sigma_{h m, t}\right)=0,
$$

where $m_{t+1} \equiv \ln M_{t+1}$ is the $\log \mathrm{SDF}, r_{t+1}^{e}(h) \equiv \ln R_{t+1}^{e}(h)$ the log-stock return on share of firm $h, \sigma_{m, t}^{2} \equiv \operatorname{var}_{t}\left(m_{t+1}\right)$ the conditional variance of the log SDF, $\sigma_{h}^{2} \equiv \operatorname{var}_{t}\left(r_{t+1}^{e}(h)\right)$ the conditional variance of log stock returns and $\sigma_{h m, t} \equiv \operatorname{cov}\left(r_{t+1}^{e}(h), m_{t+1}\right)$ the conditional covariance between $\log$ returns and the $\log$ SDF. Since our equilibrium will feature conditionally homoskedastic ex post returns, we drop the time index in $\sigma_{h}^{2}$ from the outset. By contrast, as we shall see shortly, the log-SDF will be endogenously heteroskedastic (despite the homoskedacity of its component, i.e., aggregate consumption), thereby generating a time-varying price of risk that will affect equilibrium real stock prices and excess returns. From (17), the expected log-excess return on a share of firm $h$ is then given by (see Campbell, 2003):

$$
E_{t}\left(r_{t+1}^{e}(h)-r_{t+1}^{f}\right)=-\sigma_{h m, t}-\frac{\sigma_{h}^{2}}{2} .
$$

Apart from the role of precautionary savings, which foster aggregate savings and thus lower excess returns (captured by the term $\sigma_{h}^{2} / 2$ ), expression (18) reflects the usual pricing of systematic payoff risk in complete markets general equilibrium economies. For example, an asset payoff that is highly correlated with aggregate consumption provides a poor hedge against consumption fluctuations and thus commands high expected excess returns; this effect is reflected by the negative correlation between future marginal utility of consumption and the asset return and thus a high value of $-\sigma_{h m, t}$ in (18).

Let $\hat{r}_{t+1}^{e}$ be the deviation of the log expected return from the deterministic steady state where all shocks are set to zero at all times. Along this steady state, there is no risk premium and we have $r_{t+1}^{e}(h)=r^{f}=-\ln \beta$; we may then rewrite (18) in terms of deviations from steady state as follows:

$$
E_{t}\left(\hat{r}_{t+1}^{e}(h)-\hat{r}_{t+1}^{f}\right)=-\sigma_{h m, t}-\frac{\sigma_{h}^{2}}{2} .
$$

Excess equity returns in (19) affect asset prices through the discounting of dividend streams. Thus we need to determine the two components of the right-hand-side of (19) in order to analyze their effects on real stock prices. We defer the derivation of $\sigma_{h}^{2} / 2$ to a later section, where we explain how to retrieve $\sigma_{h c}$ and $\sigma_{h}^{2}$ jointly.

Stochastic discount factor. Taking $\sigma_{h}^{2} / 2$ as given, we need to derive an expression for $\sigma_{h m, t}$, which requires an explicit expression for the equilibrium SDF. As explained earlier, going from excess returns, real interest rates and dividends to equilibrium real stock prices requires forming VAR based forecasts of all future values of these underlying determinants. We thus aim at expressing the time-varying covariance term in (19) as a function of variables that can be forecasted from the macroeconomic block of the model, while at the same time capturing the role played by

\footnotetext{
${ }^{4}$ See, e.g., Campbell (1993), and more recently Restoy and Weil (2011) for a similar derivation of approximate asset pricing expressions (in the context of Epstein-Zin preferences, rather than habit formation).
} 
time-varying risk aversion. The procedure described below delivers both these features. First let

$$
\Lambda_{t+1}=\left(C_{t+1}-b C_{t}\right)^{-\sigma} \equiv \Lambda\left(C_{t+1}, C_{t}\right)
$$

and

$$
\Theta_{t}=-\frac{C_{t} u_{11}\left(C_{t}, C_{t-1}\right)}{u_{1}\left(C_{t}, C_{t-1}\right)}=-\frac{C_{t} \Lambda_{1}\left(C_{t}, C_{t-1}\right)}{\Lambda\left(C_{t}, C_{t-1}\right)}=\frac{\sigma C_{t}}{C_{t}-b C_{t-1}}=\frac{\sigma}{1-b e^{-\Delta \hat{c}_{t}}}
$$

be the households' (local) relative risk aversion coefficient at date $t$. Taking a first-order Taylor expansion of $\Lambda\left(C_{t+1}, C_{t}\right)$ around any point $(X, Y)$ that is sufficiently close to $\left(C_{t+1}, C_{t}\right)$ we obtain

$$
\Lambda\left(C_{t+1}, C_{t}\right) \approx \Lambda(X, Y)+\Lambda_{1}(X, Y)\left(C_{t+1}-X\right)+\Lambda_{2}(X, Y)\left(C_{t}-Y\right)
$$

Provided that consumption is sufficiently smooth, so that $C_{t}$ is sufficiently close to $C_{t-1}$, we may take $(X, Y)=\left(C_{t}, C_{t-1}\right)$ as the point around which we linearize. ${ }^{5}$ Then, we can rearrange this to get:

$$
\frac{\Lambda\left(C_{t+1}, C_{t}\right)-\Lambda\left(C_{t}, C_{t-1}\right)}{\Lambda\left(C_{t}, C_{t-1}\right)} \approx \frac{\Lambda_{1}\left(C_{t}, C_{t-1}\right) C_{t}}{\Lambda\left(C_{t}, C_{t-1}\right)}\left(\frac{C_{t+1}-C_{t}}{C_{t}}\right)+\frac{\Lambda_{2}\left(C_{t}, C_{t-1}\right) C_{t-1}}{\Lambda\left(C_{t}, C_{t-1}\right)}\left(\frac{C_{t}-C_{t-1}}{C_{t-1}}\right) .
$$

This expression essentially approximates marginal utility growth (left hand side) with an appropriate weighted sum of current and past consumption growth (right hand side). We can now rewrite marginal utility growth as:

$$
\Delta \ln \Lambda\left(C_{t+1}, C_{t}\right) \equiv \Delta \lambda_{t+1} \approx-\Theta_{t}\left(\Delta \hat{c}_{t+1}-\Delta \hat{c}_{t}\right)-\sigma \Delta \hat{c}_{t}
$$

The effect of consumption growth on risk aversion follows from our assumed utility function; for example, when consumption falls relative to past consumption, so that $\Delta \hat{c}_{t}<0$, then the local curvature of the utility function increases, thereby making households more risk averse. Under the approximation in (24), innovations to the log-SDF are given by:

$$
m_{t+1}-E_{t} m_{t+1}=\Delta \ln \Lambda\left(C_{t+1}, C_{t}\right)-E_{t}\left(\Delta \ln \Lambda\left(C_{t+1}, C_{t}\right)\right)=-\Theta_{t}\left(\hat{c}_{t+1}-E_{t} \hat{c}_{t+1}\right) .
$$

We can therefore approximately express the conditional covariance between the log-SDF and the log-stock return as:

$$
\sigma_{h m, t} \approx E_{t}\left[-\Theta_{t}\left(\hat{c}_{t+1}-E_{t}\left(\hat{c}_{t+1}\right)\right)\left(r_{t+1}^{e}(h)-E_{t} r_{t+1}^{e}(h)\right)\right]=-\sigma_{h c} \Theta_{t},
$$

where $\sigma_{h c}$ has no time index since log-consumption and log-asset returns will be conditionally homoskedastic in our approximate equilibrium (see Section 5).

Substituting our expression for $\sigma_{h m, t}$ into (19), we find that expected excess returns, in terms of log-deviations from the deterministic steady state, are approximately given by:

$$
E_{t}\left(\hat{r}_{t+1}^{e}(h)-\hat{r}_{t+1}^{f}\right)=\sigma_{h c} \Theta_{t}-\frac{\sigma_{h}^{2}}{2}
$$

which is only a function of $\Delta \hat{c}_{t}$ (see (21)). In short, (27) states that rising current risk aversion,

\footnotetext{
${ }^{5}$ This approximation is in fact more accurate than linearizing $\Lambda\left(C_{t+1}, C_{t}\right)$ around steady state, since consumption persistence implies that $C_{t}$ is at least as close to $C_{t-1}$ as it is to its steady state value.
} 
$\Theta_{t}$, raises expected excess returns and therefore it increases the premium required for holding risky shares. This effect is scaled by the consumption risk associated with holding share $h$, i.e. the covariance of ex post returns with next period's consumption $\sigma_{h c}$. Loosely speaking, while the consumption risk of the stock market $\sigma_{h c}$ is constant, the price of risk $\Theta_{t}$ is time-varying because households become more risk-averse in recessions, due to the habit formation specification. The key advantage of our way of linearizing the marginal utility of current consumption is that it allows us to arrive at a tractable expression for expected excess returns that preserves the key source of changes in risk aversion in the model (i.e., the changes in current consumption relative to past consumption), and which would by construction would be lost with a standard log-linearization about steady state consumption. ${ }^{6}$

4.3. Stock prices. Having derived expressions for all the underlying determinants of real stock prices (i.e., dividends, risk-free rates and expected excess returns), we may now turn to the implied equilibrium real stock prices. This may be done by using the log-linear present value model of Campbell and Shiller (1988). More specifically, linearizing (16) around the deterministic steady state and using (13), we may write ex post log-stock returns as follows:

$$
\hat{r}_{t+1}^{e}(h)=\beta \hat{q}_{t+1}(h)+(1-\beta) \hat{d}_{t+1}-\hat{q}_{t}(h),
$$

where $\hat{q}_{t}(h)$ denotes the log-deviation of firm $h$ 's share price from the deterministic steady state. Note that the unconditional means of $\hat{r}_{t}^{e}(h)$ and $\hat{q}_{t}(h)$ are different from zero here, since holding risky shares requires a positive average returns premium (i.e. $E\left(\hat{r}_{t+1}^{e}(h)\right)>0$ ) that depresses average real stock prices (i.e. $\hat{q}_{t}(h)<0$ ), provided that the portfolio risk effect in $(27)$ dominates the precautionary savings effect (i.e. $\sigma_{h c} \Theta_{t}-\sigma_{h}^{2} / 2>0$ ). However, the approximation in (28) will remain valid as long as fluctuations are sufficiently small, that is as long as $E\left(\hat{r}_{t+1}^{e}(h)\right)$ is sufficiently close to $E\left(\hat{r}_{t+1}^{f}\right)=0$. On average, we have $E\left(\hat{r}_{t+1}^{e}(h)\right)=-(1-\beta) E\left(\hat{q}_{t}(h)\right)$ since $E\left(\hat{d}_{t+1}\right)=0$ in $(28)$.

Solving (28) for $\hat{q}_{t}(h)$, substituting it into (19) and applying the expectation operator on both sides, we get

$$
\hat{q}_{t}(h)=\beta E_{t}\left(\hat{q}_{t+1}(h)\right)+(1-\beta) E_{t} \hat{d}_{t+1}-\hat{r}_{t+1}^{f}-\sigma_{h c} \Theta_{t}+\frac{\sigma_{h}^{2}}{2} .
$$

Finally, iterating (29) and rearranging under the condition that no rational bubble occurs (i.e., $\left.\lim _{n \rightarrow \infty} \beta^{n} \hat{q}_{t+n}(h)<\infty\right)$, the share price of firm $h$ may be written as

$$
\hat{q}_{t}(h)=-\frac{\mu}{1-\beta}+(1-\beta) \sum_{j=0}^{\infty} \beta^{j} E_{t}\left(\hat{d}_{t+1+j}\right)-\sum_{j=0}^{\infty} \beta^{j} E_{t}\left(\hat{r}_{t+1+j}^{f}\right)-\sigma_{h c} \sum_{j=0}^{\infty} \beta^{j} E_{t}\left(\hat{\Theta}_{t+j}\right),
$$

where $\mu=\sigma_{h c} \bar{\Theta}-\sigma_{h}^{2} / 2$ is the mean equity premium, $\bar{\Theta}=\sigma /(1-b)$ is the mean risk aversion coefficient and $\hat{\Theta}_{t}=\Theta_{t}-\bar{\Theta}$ its level-deviation from the mean.

Equation (30) is intuitive: real stock prices increase with future dividends (second term), but decrease with current and future risk-free rates (third term) and risk aversion (fourth term). The constant (first term) just reflects the difference between the average stock price along the stochastic

\footnotetext{
${ }^{6}$ This way of linearizing the consumption Euler equation (i.e., around current consumption or consumption growth, rather than their steady state counterparts) has proven useful elsewhere. One example is the literature on precautionary savings behavior, where this technique also allows to preserve important properties of the nonlinear Euler equation that would be lost otherwise (e.g., Dynan, 1993; Gourinchas and Parker, 2001).
} 
equilibrium and its value at the deterministic steady state, around which the linearization was taken. For example, a greater covariance between consumption and returns, $\sigma_{h c}$, makes asset $h$ more risky and thus lowers its average value, relative to the deterministic steady state; but higher return risk fosters precautionary savings, which tends to raise asset demand and prices, relative to the deterministic steady state. All summation terms are centered around their unconditional mean. The corresponding centered asset-price variable is simply $\tilde{q}_{t}(h) \equiv \hat{q}_{t}(h)+\mu /(1-\beta)$.

Note that expression (30) is not quite yet operative because real stock prices actually appear on both sides of it: the covariance term $\sigma_{h c}$ determines how time-variations in risk aversion affect prices, but $\sigma_{h c}$ is not a deep parameter of the model. It is an endogenous parameter that depends on equilibrium asset prices. Similarly, both $\sigma_{h}^{2}$ and $\sigma_{h c}$ enter the constant term while they are endogenously determined in equilibrium. In perfectly competitive economies, the ex post return on stocks would be given by the marginal product of capital and its first and second moments could be directly extracted from the macroeconomic block of the model (as, e.g., Jermann, 1998). This cannot be done in our imperfectly competitive model, so we must recover ex post return from dividends and prices using (13), (28) and (30). However, we show in the next section that under certain assumptions, there is only one possible combination of $\sigma_{h}^{2}$ and $\sigma_{h c}$ that is consistent with (30). This can be recovered from (30) and the VAR representation of the macro dynamics of the model. Finally, since dividends and risk-free rates in (30) are identical across firms in equilibrium, so are the parameters $\sigma_{h}^{2}$ and $\sigma_{h c}$ and the implied prices $\hat{q}_{t}(h)$. We may thus aggregate share prices into a single price index, i.e., $\hat{q}_{t}=\hat{q}_{t}(h)$, for all $h \in[0,1]$.

\section{Model SOlution}

Our goal is to compute the reaction of real stock prices to an unexpected policy shock, where the three channels emphasized above (dividends, real interest rates, excess returns) play an active role in generating this reaction. We thus proceed as follows.

The first step is to solve for the joint dynamics of all variables that are log-linearized around the steady state. These variables are collected into a vector

$$
\chi_{t}=\left[\hat{y}_{t}, i_{t}, \pi_{t}, \pi_{t}^{w}, \hat{s}_{t}, \hat{\omega}_{t}, \hat{d}_{t}, \hat{r}_{t+1}^{f}, \hat{z}_{1 t}, \hat{z}_{2 t}\right]^{\prime}
$$

where $\hat{z}_{1 t}=\hat{z}_{t}$ and $\hat{z}_{2 t}=0 \hat{z}_{2 t-1}+\varepsilon_{t}$. Note that $\hat{r}_{t+1}^{f}=\hat{\imath}_{t}-E_{t}\left(\pi_{t+1}\right)$ is the ex ante real interest rate and thus known at date $t .^{7}$ We are then looking for a solution to the stochastic system of linear difference equations summarized in

$$
E_{t}\left[\Psi_{0} \chi_{1, t+1}+\Psi_{1} \chi_{1, t}+\Psi_{2} \chi_{1, t-1}+\Phi_{0} \chi_{2, t+1}+\Phi_{1} \chi_{2, t}\right]=0
$$

where

$$
\chi_{1 t}^{\prime}=\left[\hat{y}_{t}, i_{t}, \pi_{t}, \pi_{t}^{w}, \hat{s}_{t}, \hat{\omega}_{t}, \hat{d}_{t}, \hat{r}_{t+1}^{f}\right]^{\prime} \text { and } \chi_{2 t}^{\prime}=\left[\hat{z}_{1 t}, \hat{z}_{2 t}\right]^{\prime}
$$

and $\Psi_{i}, i=0,1,2$ and $\Phi_{j}, j=0,1$ are conformable matrices that are defined via equations governing the dynamics of $\chi_{t}$, i.e. (1), (3), (7), (8), (9), (10), (11), (13), and (14).

We employ a standard undetermined coefficients method to solve for the dynamics of this system, and we may write the solution for the dynamics of $\chi_{t}$, if it exists and is unique, in a

\footnotetext{
${ }^{7}$ Not all entries in $\chi_{t}$ are state variables. This vector is simply a compact way of summarizing all the relevant linearized and log-linearized variables of the model.
} 
compact form as follows: ${ }^{8}$

$$
\chi_{t}=F \chi_{t-1}+L \epsilon_{t}
$$

where $F$ and $L$ are conformable matrices and where:

$$
\epsilon_{t}=\left[\begin{array}{l}
u_{t} \\
\varepsilon_{t}
\end{array}\right] \sim N(0, \Sigma), \Sigma=\left[\begin{array}{cc}
\sigma_{u}^{2} & \sigma_{u \varepsilon} \\
\sigma_{u \varepsilon} & \sigma_{\varepsilon}^{2}
\end{array}\right] .
$$

The second step is to use (32) in order to derive an expression for the stock price as a function of present and past values of $\chi$. At this stage, all sequences that enter the summation terms in (30) can be forecasted using (32), apart from $\hat{\Theta}_{t}$ which is a nonlinear function of $\Delta \hat{c}_{t}$ (see (21)). However, linearizing (21) and using the fact that $\hat{c}_{t}=\hat{y}_{t}$, we can write the centered risk aversion coefficient as:

$$
\hat{\Theta}_{t}=\Theta_{t}-\bar{\Theta} \approx-\left(\frac{\bar{\Theta} b}{1-b}\right) \Delta \hat{y}_{t}
$$

which can now also be extracted from (32). We are also now in position to confirm the joint log-normality of SDF and returns. Under the dynamics (32) and the maintained assumption that the underlying innovations are i.i.d. normal, all variables in $\chi_{t}$, are conditionally normally distributed and homoskedastic. It follows that $d_{t}$ in (13), $\hat{r}_{t+1}^{f}$ in (14) and $\hat{\Theta}_{t}$ in (34) are all conditionally normally distributed and homoskedastic, and so are the log-deviations from steady state of real stock prices, $\hat{q}_{t}(h)$ in (30), and stock returns, $\hat{r}_{t+1}^{e}(h)$ in (28). Finally, the conditional normality of $\hat{c}_{t+1}$ implies that marginal utility growth, $\Delta \lambda_{t+1}$, in (24), and hence the log-SDF, $m_{t+1}=\ln \beta+\Delta \lambda_{t+1}$, are also conditionally normally distributed. Thus, $R_{t+1}^{e}(h)=e^{-\ln \beta+\hat{r}_{t+1}^{e}(h)}$ and $M_{t+1}=e^{m_{t+1}}$ are confirmed to be conditionally lognormally distributed, as we assumed when going from (15) to (17).

Now let $\mathbf{e}_{k}$ denote a column indicator vector that picks a generic variable $k$ from the vector $\chi_{t}$, i.e. a vector such that $k_{t}=\mathbf{e}_{k}^{\prime} \chi_{t}$. Expectations of future dividends, risk-free rates and risk aversion coefficients are then given by

$$
\begin{gathered}
E_{t}\left(\hat{d}_{t+1+j}\right)=\mathbf{e}_{d}^{\prime} F^{j+1} \chi_{t}, E_{t}\left(\hat{r}_{t+1+j}^{f}\right)=\mathbf{e}_{r f}^{\prime} F^{j} \chi_{t}, \\
\text { and } E_{t}\left(\hat{\Theta}_{t+1+j}\right)=\mathbf{e}_{y}^{\prime}\left(F^{j+1}-F^{j}\right) \chi_{t}, \text { for } j=0,1, \ldots
\end{gathered}
$$

Then, substituting these sequences into (30) and using the fact that $\hat{q}_{t}=\hat{q}_{t}(h) \forall h \in[0,1]$, we can now rewrite the value of the stock market index only as a function of constants and the

\footnotetext{
${ }^{8}$ The system can be solved with any of the known algorithms or toolboxes that are available for such problems. We use Christiano's (2002) general approach. Christiano (2002) expresses the solution to the system as

$$
\chi_{1 t}=A \chi_{1, t-1}+B \chi_{2 t} .
$$
}

Here however, it is more convenient to write the decomposition in terms of white noise shocks, so that we can work with the expectations more easily. This can be done by writing

$$
\chi_{t}=\left(\begin{array}{c}
\chi_{1 t} \\
\chi_{2 t}
\end{array}\right)=\underbrace{\left(\begin{array}{cc}
A & B P \\
\mathbf{0} & P
\end{array}\right)}_{=F}\left(\begin{array}{l}
\chi_{1, t-1} \\
\chi_{2, t-1}
\end{array}\right)+\underbrace{\left(\begin{array}{c}
B \\
I_{2}
\end{array}\right)}_{=L}\left(\begin{array}{c}
u_{t} \\
\varepsilon_{t}
\end{array}\right),
$$

where

$$
P=\left(\begin{array}{ll}
\rho & 0 \\
0 & 0
\end{array}\right)
$$


current and last period's value of the vector $\chi$ :

$$
\begin{aligned}
\hat{q}_{t}= & \underbrace{-\frac{\mu}{1-\beta}}_{\text {constant }}+\underbrace{(1-\beta) \mathbf{e}_{d}^{\prime}(I-\beta F)^{-1} F \chi_{t}}_{\text {dividends contribution }}-\underbrace{\mathbf{e}_{r f}^{\prime}(I-\beta F)^{-1} \chi_{t}}_{\text {real interest rates contribution }} \\
& \underbrace{\frac{b \bar{\Theta} \sigma_{h c}}{(1-b)} \mathbf{e}_{y}^{\prime}\left[\chi_{t-1}-(1-\beta)(I-\beta F)^{-1} \chi_{t}\right]}_{\text {excess returns contribution }},
\end{aligned}
$$

where $I$ is a $10 \times 10$ identity matrix.

The last step in computing equilibrium real stock prices is to determine $\sigma_{c}^{2}, \sigma_{h}^{2}$ and $\sigma_{h c}$. First note that we can easily retrieve $\sigma_{c}^{2}$ from the linearized macro block by rewriting $\hat{c}_{t}=\hat{y}_{t}=\mathbf{e}_{y}^{\prime} \chi_{t}$ and using (32) to get

$$
\sigma_{c}^{2}=E_{t}\left[\left(\hat{y}_{t+1}-E_{t} \hat{y}_{t+1}\right)^{2}\right]=\mathbf{e}_{y}^{\prime} L \Sigma L^{\prime} \mathbf{e}_{y} .
$$

Regarding $\sigma_{h}^{2}$, we first rewrite (37) as

$$
\hat{q}_{t}=\tau_{0}+\tau_{1}^{\prime} \chi_{t}+\tau_{2}^{\prime} \chi_{t-1}
$$

where

$$
\begin{aligned}
\tau_{0} & =-\frac{\mu}{1-\beta}, \\
\tau_{1}^{\prime} & =(1-\beta) \frac{b \bar{\Theta} \sigma_{h c}}{1-b} \mathbf{e}_{y}^{\prime}(I-\beta F)^{-1}-\mathbf{e}_{r f}^{\prime}(I-\beta F)^{-1}+(1-\beta) \mathbf{e}_{d}^{\prime}(I-\beta F)^{-1} F, \\
\tau_{2}^{\prime} & =-\frac{b \bar{\Theta} \sigma_{h c}}{1-b} \mathbf{e}_{y}^{\prime} .
\end{aligned}
$$

Then, from (28), innovations to ex post returns are given by:

$$
\begin{aligned}
r_{t+1}^{e}(h)-E_{t}\left(r_{t+1}^{e}(h)\right) & =\beta\left(\hat{q}_{t+1}-E_{t} \hat{q}_{t+1}\right)+(1-\beta)\left(\hat{d}_{t+1}-E_{t}\left(\hat{d}_{t+1}\right)\right) \\
& =\left(\beta \tau_{1}+(1-\beta) \mathbf{e}_{d}\right)^{\prime}\left(\chi_{t+1}-E_{t} \chi_{t+1}\right) .
\end{aligned}
$$

Using the above expression, we can derive the conditional covariance of consumption and ex post returns as follows:

$$
\sigma_{h c}=\left(\beta \tau_{1}+(1-\beta) \mathbf{e}_{d}\right)^{\prime} L \Sigma L^{\prime} \mathbf{e}_{y} .
$$

Since $\tau_{1}$ is linear in $\sigma_{h c}$, it is straightforward to retrieve it from the above expression once we have evaluated the matrices $F$ and $L$ from the rest of the parameter values. Similarly once we have $\sigma_{h c}$, we can also get the conditional variance $\sigma_{h}^{2}$, which is given by

$$
\sigma_{h}^{2}=\left(\beta \tau_{1}+(1-\beta) \mathbf{e}_{d}\right)^{\prime} L \Sigma L^{\prime}\left(\beta \tau_{1}+(1-\beta) \mathbf{e}_{d}\right) .
$$

For a given $\chi_{t}$, all terms and parameters in (37) are now pinned down by (21), the matrices $F$ and $L$ in (32) and the expressions for $\sigma_{c}^{2}, \sigma_{h}^{2}$ and $\sigma_{h c}$ given by (38), (45) and (44). The vector $\chi_{t}$ is endogenously determined by the exogenous shock vector through (32). We thus have all the elements necessary for the computation of the impact and propagation of a nominal interest rate shock on the stock market, as well as for its decomposition into the relative contributions of the 


\begin{tabular}{|lcl|lrl|}
\hline IES coefficient & $\sigma=$ & 1.00 & Responsiveness to inflation & $\rho_{\pi}=1.50$ \\
Labour supply coef. & $\eta=$ & 0.00 & Responsiveness to output & $\rho_{y}=0.60$ \\
Habit persistence & $b=$ & 0.80 & Phillips & $\kappa_{p}=0.2707$ \\
Discounting & $\beta=$ & 0.99 & Wage Phillips & $\kappa_{w}=0.0121$ \\
Interest rate persistence & $\gamma=$ & 0.85 & Elast. of demand for goods & $\theta_{p}=4.00$ \\
Fraction of unchanged prices & $\psi_{p}=$ & 0.60 & Elast. of demand for labour & $\theta_{w}=4.00$ \\
Fraction of unchanged wages & $\psi_{w}=$ & 0.90 & Shock for technology & $\alpha=0.99$ \\
Conditional st. dev. of $r_{t}^{e}$ & $\sigma_{h}=$ & 0.0242 & Standard deviation of tech shock & $\sigma_{u}=0.025$ \\
Conditional st. dev. of $c_{t}$ & $\sigma_{c}=$ & 0.0049 & Standard deviation of mon shock & $\sigma_{\varepsilon}=0.0027$ \\
Conditional cov. of $r_{t}^{e}, c_{t}$ & $\sigma_{h c}=$ & 0.0001 & Covariance of tech and mon shock & $\sigma_{u \varepsilon}=0$ \\
\hline
\end{tabular}

Table 2: Baseline parameterisation.

three underlying stock price determinants.

The experiment we make is he following. We start from a point in time $t=-1$ where all variables are at their unconditional mean, so that $\chi_{-1}=0$ and thus $\hat{q}_{-1}=-\mu /(1-\beta)$. At date 0 , a once occurring unexpected policy shock $\varepsilon_{0}$ occurs that raises the level of the nominal interest rate by 25 basis points, i.e., a shock in (10) that generates $\Delta i_{0}=0.25 .^{9}$ We then compute the instantaneous stock price growth triggered by this policy change. We also plot the normalized dynamic adjustment of real stock prices, $\hat{q}_{t}, t=1,2, \ldots$, as well as that of the rest of the variables of interest in the form of impulse-response functions. Finally, we decompose the multiplier $\Delta \hat{q}_{0} / \Delta i_{0}$ into the three relevant components using (37). This is given by

$$
\begin{aligned}
\mathcal{M}_{q} \equiv & \frac{\Delta \hat{q}_{0}}{\Delta i_{0}}=\underbrace{(1-\beta) \mathbf{e}_{d}^{\prime}(I-\beta F)^{-1} F L\left[\begin{array}{c}
0 \\
\varepsilon_{0}
\end{array}\right]}_{\text {dividend contribution }}-\underbrace{\mathbf{e}_{r f}^{\prime}(I-\beta F)^{-1} L\left[\begin{array}{c}
0 \\
\varepsilon_{0}
\end{array}\right]}_{\text {risk free rate contribution }} \\
& \underbrace{\frac{\bar{\Theta} \sigma_{h c} b}{(1-b)} \mathbf{e}_{y}^{\prime}(1-\beta)(I-\beta F)^{-1} L\left[\begin{array}{c}
0 \\
\varepsilon_{0}
\end{array}\right]}_{\text {risk aversion contribution }} .
\end{aligned}
$$

The multipliers obtained in this way are consistent with the way the evidence is reported, since the latter documents the effect of a level-variation of the Central Bank's nominal interest rate (e.g., a 25 basis points increase) on the growth of the stock market index (e.g., a fall of the index by $1 \%)$.

\section{Results}

6.1. Baseline Parameterization. We assume a quarterly specification for the parameters of the model. Our baseline parameterization is put forth in Table 2; we discuss each of these parameters in turn. The parameter $\sigma$ is typically assumed to vary between 1 and 5 in most of the macroeconomics literature. We choose $\sigma=1$ which is more in line with the business cycle literature. Next, we set the parameter $\eta$ to be 0 , which is a common assumption. As it will turn out, the choice of $\eta$ does not significantly affect the results. For the discounting we choose $\beta=0.99$ which is typical for quarterly calibrations. The habit parameter is set to $b=0.8$ following existing literature such as Jermann (1998). Turning to the parameters of the Taylor rule, for the VolkerGreenspan era, a robust estimate for the US is around $\gamma=0.85$. For example, Clarida, Gali and

\footnotetext{
${ }^{9}$ The required size of this shock can be determined once the parameter values are set (see next section).
} 
Gertler (2000) calculate $\gamma \in[0.73,0.88]$ depending on which sample/measure is used. Judd and Rudebusch (1998) suggest $\gamma \in[0.56,0.73]$, Amato and Laubach (1999) give $\gamma \in[0.78,0.92]$ and Kozicki (1999) gives $\gamma \in[0.75,0.82]$.

Conventional estimates for the response parameters in the Taylor rule are $\rho_{\pi} \approx 1.5$ and $\rho_{y}<$ 1.0, but estimates may vary substantially from one paper to the other. For example Judd and Rudebusch (1998) estimate $\rho_{\pi} \in[1.46,1.69]$ and $\rho_{y} \in[0.36,0.99]$, Clarida et al. (2000) give $\rho_{\pi} \in$ $[1.97,2.15]$ and $\rho_{y} \in[0.55,1.49]$ and Kozicki (1999) gives $\rho_{\pi} \in[1.05,1.66]$ and $\rho_{y} \in[0.42,0.52]$. We choose $\rho_{\pi}=1.5$ and $\rho_{y}=0.6$ in our benchmark experiment. ${ }^{10}$

The elasticities of the demands for good and labour varieties are set to $\theta_{p}=\theta_{w}=4$. In the literature, these parameters vary between 3 and 10, although the estimates of Christiano et al. (2005) have a larger variation. Finally, we set the degree of price rigidity $\psi_{p}$ to 0.6 and the degree of wage rigidity $\psi_{w}$ to 0.9 . Highly rigid wages ensure that firm profits and thus dividends are procyclical.

There are four more parameters to be determined, namely $\alpha, \sigma_{u}, \sigma_{\varepsilon}$ and $\sigma_{u \varepsilon}$. First, we set $\alpha=0.99$ and $\sigma_{u}=0.025$. This is within reasonable limits and captures volatility of output growth from US data. Moreover, the literature reports numbers for $\sigma_{u}$ between 0.008 and 0.04 (see Wouters and Smets, 2003, Danthine and Kurman, 2004, Collard and Dellas, 2005 and Rabanal and Rubio-Ramirez, 2005). The persistence parameter is somewhat higher than the usually reported numbers around 0.96 . Next, we set $\sigma_{\varepsilon}=0.0027$. This number is calculated so that typical surprise moves in the nominal interest rate be of 25 basis points. As we explain in section 6.2 , the actual monetary policy shock $\varepsilon_{0}$ has to be adjusted with the elasticity $L_{22}$ in order to ensure that $i$ changes by 25 basis points, and this requires its standard deviation $\sigma_{e}$ to be set at a slightly larger value. Last, we set $\sigma_{u \varepsilon}=0$, since the underlying assumption behind our thought experiment is that $\varepsilon_{t}$ represents monetary policy surprises and should thus be treated as a non-systematic reaction to changes in aggregate supply; any correlation between monetary policy and technology shocks is by construction internalized in the Taylor rule.

6.2. Results. In order to simulate the reaction of real stock prices to 25 basis points increase in the central bank rate and generate impulse-response functions, we first need to calculate the size of the shock $\varepsilon_{0}$ that does generate such a change. We have that

$$
0.25=\Delta i_{0}=\mathbf{e}_{i}^{\prime} L \epsilon_{0}=L_{22} \varepsilon_{0} \Longrightarrow \varepsilon_{0}=0.25 / L_{22},
$$

where $L_{22}$ is the elasticity of the nominal interest rate with respect to the monetary innovation. We thus impose a shock of size $0.25 / L_{22}$, and then recover model-generated semi-elasticities that are directly comparable to those in Table 1 by computing $\Delta \hat{q}_{0} / \Delta i$.

Figure 1 provides the impulse response functions of all variables of interest following a one percentage point increase in the nominal interest rate. Table 3 gives the proportional change in real stock prices and ex post excess returns following this shock, as well as the breakdown of those

\footnotetext{
${ }^{10}$ As discussed by Clarida, Gali and Gertler (2000, Section4), the pre-Volcker period was probably characterised by a value of $\rho_{\pi}$ lower than one, leading to the violation of the Taylor principle and, in the context of the New Keynesian model, to the appearance of multiple self-fulfilling equilibria. In these cases, learnability criteria may be used to select the appropriate equilibrium (see, e.g., McCallum, 2003). The evidence that motivates our analysis is based on data collected after the Volcker shock, during which the Taylor principle is commonly agreed to have been satisfied.
} 

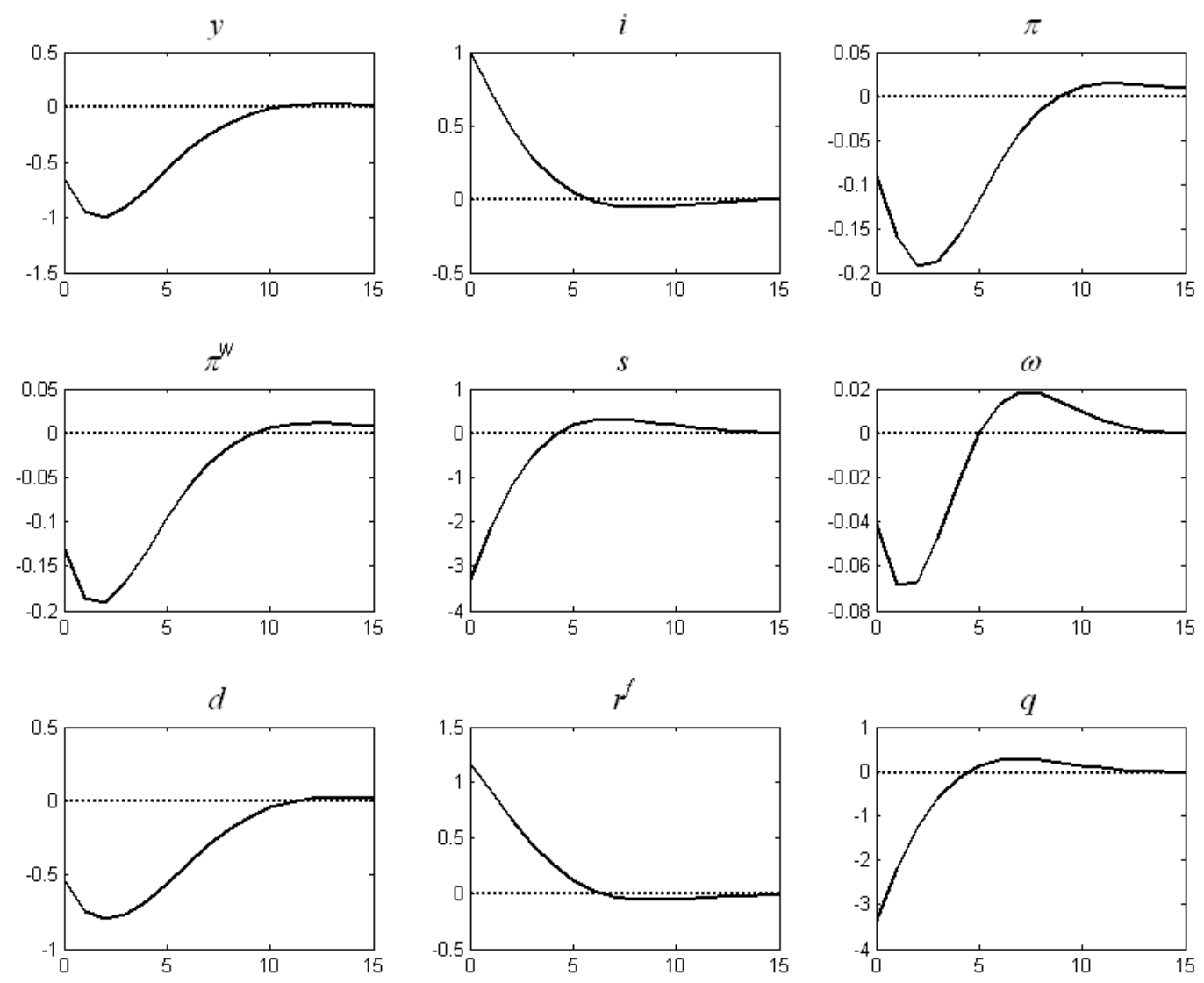

Figure 1: Impulse responses to an unexpected monetary policy shocks. Note: The responses are scaled so as to correspond to a change in the nominal interest rate of one percentage point.

in the three channels. The corresponding effect on ex post excess returns is obtained as a weighted average of price and dividend changes, i.e. $\Delta \hat{r}_{0}^{e}(h)=\beta \Delta \hat{q}_{0}+(1-\beta) \Delta \hat{d}_{0}$.

The dynamic adjustment of macroeconomic variables to a nominal interest rate shock is roughly consistent with empirical impulse-responses (e.g. Christiano et al., 2005). The nominal interest rate rise is contractionary, which lowers both price and wage inflation, the overall implication of both being a mildly procyclical real wage adjustment. The indexation of not re-optimized prices and wages on their past respective inflation rates produces inertia in those variables and hence humpshaped responses to the initial shock. Similarly, the presence of past output, due to households' consumption habits, jointly with future output in the dynamic IS curve generates output inertia and a hump-shaped response of this variable to the shock. ${ }^{11}$ In contrast, real stock prices are purely forward-looking and hence display no inertia; it follows that their maximal departure from their steady state value takes place at the very time of the shock. Finally, staggered wage adjustment generates procyclical profits and dividends, as is consistent with the data; with fully flexible wages, labour market adjustments in the face of a falling labour demand would cause real wages and thus firms production costs to shoot down, thereby generating countercyclical profits and dividend

\footnotetext{
${ }^{11}$ See Woodford (2003, chap. 3 and 5) for further discussion of inflation and output inertia in shaping the response of those variables to underlying shocks.
} 


\begin{tabular}{|ccccc|}
\hline & Total Impact & Dividend Contr. & Real Int. Rate Contr. & Excess Returns Contr. \\
\hline \hline $\mathcal{M}_{q}$ & -3.3079 & -0.0443 & -3.2634 & -0.0002 \\
$\mathcal{M}_{e r}$ & -3.2802 & -0.0492 & -3.2308 & -0.0002 \\
\hline
\end{tabular}

Table 3: Model predicted multipliers of stock prices and excess returns, with respect to a surprise increase in the nominal rate, for the baseline parametrization .

payments.

Our baseline calibration generates a stock market impact multiplier of -3.3079 , which is well inside the range of available empirical estimates. Although this range may appear to be large and easy to fall into quantitatively, recall that our parameters were chosen to be in line with the business cycle literature and were thus not designed to match the empirical value of the stock price multiplier. This result suggests that our baseline New Keynesian model provides a potential general equilibrium explanation for the observed stock market reaction to monetary policy shocks.

This conclusion deserves one cautious note, however. The decomposition of ex post excess returns following the policy shock that we obtain from the model (second line of Table 3) gives a surprisingly small role to variations in ex ante excess returns and a comparatively large one to changes in real interest rates. The relatively small contribution of changes in expected excess returns can be understood as follows. From the last summation term in (30), it is apparent that the excess returns contribution to the price multiplier is governed by (i) the conditional covariance between consumption and asset return, $\sigma_{h c}$, or consumption risk of the stock market and (ii) the variability of the (local) relative risk aversion coefficient, $\hat{\Theta}_{t}$, in response to aggregate shocks, i.e., the "price of risk". Moreover, from equation (34), the latter is itself the product of (minus) the change in logoutput, $-\Delta y_{t}$ (which is also $-\Delta c_{t}$ in the model), multiplied by the factor $\bar{\Theta} b /(1-b)=\sigma b /(1-b)^{2}$, which scales the impact on households' risk aversion of the consumption fall that follows the shock. Now, the very nature of habit formation makes households reluctant to change current consumption relative to past consumption and thus limits the consumption response to exogenous shocks, as soon as consumption is optimally chosen by households (rather than being exogenously given as in pure exchange economies, see the discussion in Lettau and Uhlig, 2000). Formally, this shows up in the fact that in equilibrium the value of $\left|\Delta y_{t}\right|$ at the time of the shock is smaller when $b>0$ in (7) than when $b=0$, which in turn tends to limit the corresponding change in risk aversion, $\hat{\Theta}_{t}$. Second, our baseline value for the intertemporal elasticity of substitution parameter (i.e., $\sigma=1$ ) keeps the scaling factor $\sigma b /(1-b)^{2}$ relatively low, thereby preventing small consumption changes to induce large changes in risk aversion. Finally, the limited conditional consumption variability after a shock due to habit formation implies a small conditional covariance between consumption and ex post stock returns, $\sigma_{h c}$ (see Table 2). Hence, all three factors determining the size of the excess returns contribution (i.e., $\sigma_{h c}, \bar{\Theta} b /(1-b)$ and $-\Delta y_{t}$ ) tend to be small.

This prediction of a small excess returns contribution to the multipliers is in contrast to the VAR based decomposition of empirical returns proposed by Bernanke and Kuttner (2005), which suggests that ex post excess returns variations following a nominal interest rate shock work predominantly through variations in ex ante excess returns, with a small contribution of real interest rate changes. However, Bernanke and Kuttner's result of a small real interest rate contribution naturally follows from their very quick estimated decay of the real interest rate following the policy shock: real rates deviations from the mean have a half-life of no more than two months and have completely died 


\begin{tabular}{|lcccc|}
\hline \multicolumn{1}{|c}{ Parameters } & $\mathcal{M}_{q}$ & Dividends & Real Interest rates & Excess Returns \\
\hline \hline \multicolumn{1}{c}{ Baseline } & -3.3079 & -0.0443 & -3.2634 & -0.0002 \\
\hline \hline$\sigma \in[1,5]$ & -3.3079 to -4.5481 & -0.0093 to -0.0443 & -4.5388 to -3.2634 & -0.0000 to -0.0002 \\
$b \in[0.5,0.9]$ & -3.2309 to -3.5195 & -0.0394 to -0.0472 & -3.1914 to -3.4722 & -0.0000 to -0.0002 \\
$\rho_{\pi} \in[1.05,1.65]$ & -3.4657 to -3.2650 & -0.0477 to -0.0433 & -3.4084 to -3.2216 & -0.0096 to -0.0001 \\
$\rho_{y} \in[0.3,1.50]$ & -3.9555 to -2.4591 & -0.0652 to -0.0255 & -3.8571 to -2.4334 & -0.0000 to -0.0002 \\
$\gamma \in[0.55,0.95]$ & -1.5342 to -7.6912 & -0.0110 to -0.1476 & -1.5232 to -7.5370 & -0.0000 to -0.0066 \\
\hline
\end{tabular}

Table 4: Sensitivity Analysis.

out after four. With such a rapid reversion of real rates, these are bound to have little effect on real stock prices since the latter ultimately depend on the infinite sequences of future real rates, dividends and excess returns. Although this speed of adjustment is not necessarily inconsistent with previous estimates based on monthly data (see Bernanke and Mihov, 1998), the quarterly macroeconomic evidence on which our model builds typically documents a much slower reversion of real interest rates following an exogenous policy shock and would thus imply a much larger role for such rates in explaining the stock market response to the shock (e.g., Amato and Laubach, 2003; Boivin and Giannoni, 2002; Christiano et al., 2005).

6.3. Sensitivity Analysis. We have performed various robustness checks. After having varied all parameters of the model, we found our measure $\mathcal{M}_{q}$ to be very robust to changes in most of them. However, $\mathcal{M}_{q}$ is somewhat sensitive to some of them, notably the utility parameters $\sigma$ and $b$ and the Taylor rule parameters $\gamma, \rho_{\pi}$ and $\rho_{y}$. These are the parameters that have a direct effect on the behavior of consumption (utility parameters) and the real interest rates (Taylor rule parameters through their effects on nominal interest rates), i.e. the two variables that are relevant for understanding the breakdown of the impact of the shock on real stock prices. Table 4 provides the ranges of variation of $\mathcal{M}_{q}$, as well as the variation of the size of the three channels, when we vary these parameters within admissible ranges. Even if plausible variations of the deep parameters in Table 4 may significantly affect the predicted value of the price multiplier, it turns out that almost all implied values of it stay within the interval consistent with the empirical studies (with the exception of somewhat extreme values of $\gamma$ ). Similarly, such parameter changes do not alter the broad features of our impact decomposition, thus confirming the main conclusions drawn from the baseline specification. Finally, when calculating the relative contributions of each component to $\mathcal{M}_{q}$ we find that these change very little, reinforcing our claim that our main result is robust to parameter changes.

We have also performed some sensitivity checks with respect to some structural assumptions of the model. For example, and as we mentioned earlier, considering partial rather than full indexation of non-optimized prices and wages in (3) and (8) turns out to affect our baseline results insignificantly. Similarly, considering a form of long-memory habit, leaves the results practically unaffected. Finally, the same applies to using several variations of the Taylor rule, including forward looking versions.

6.4. Accuracy and comparison of results with other methods. As an additional robustness check, we also compare the multipliers obtained with our approximation to those obtained via standard first, second and third order log perturbations of the equilibrium condition that charac- 
terizes real stock prices, i.e. (15). For all equilibrium conditions apart from (15), we keep working with their log-linear approximations. The aim of this exercise is to provide an assessment of the quality of the approximation in (46).

We replicate the baseline experiment of a 25 basis points surprise increase in the nominal interest rate and report the corresponding stock price and excess returns multipliers for three alternative methods. In the top rows of Table 5, we provide the multipliers calculated with our method, as well as for the purely log-linear dynamic system (column 2) and for the systems where real stock prices are approximated by a second- or third-order perturbation (columns 3 and 4). ${ }^{12}$ As expected, the multipliers for the log-linear version of the model are those obtained with our approximation minus the excess returns contribution in (46) since, by construction, our approximation is the same as a log-linear approximation with the additional term containing $\Theta_{t}$ in the equation for real stock prices. The multipliers under log second-order perturbation are somewhat smaller than those under third-order approximation. For the former, uncertainty matters only for the constant of the dynamic approximate solution (see Schmitt-Grohe and Uribe, 2004). For the latter, as is also true for our approximation, the characteristics of the shocks (i.e. the covariance matrix $\Sigma$ ) matter for the coefficients of the solution dynamics. In other words, running a policy experiment with a 25 basis points surprise nominal interest rate shock and normalizing the multiplier to correspond to a 1 percentage point increase is not equivalent to running an experiment with a nominal interest rate shock of size 100 basis points. It is, however, possible that these two multipliers are not far from each other quantitatively, if the curvature of the approximated function around the approximation point is not high. This is examined in the last two rows of Table 6, which reports all multipliers under the policy experiment of a 100 basis points surprise increase in the policy rate. The numbers reported are quite close to those from the baseline experiments, confirming the above insight, i.e. that the Euler equation has low curvature, and therefore local approximations do reasonably well.

To further reinforce this point, also check the accuracy of our method by performing some simple, informal tests based on the insights of Den Haan and Marcet (1994). We run $N=10,000$ simulations of $T=3500$ periods, of which we discard the first 500 before reporting statistics. First, we generate artificial time-series of all variables using the log-linear solution dynamics of the model, except for real stock prices for which we use our approximate expression (37). Then, using the level variables, we calculate the errors generated by evaluating (15). If the method is accurate, then these errors should be small relative to the long run average of stock prices. Indeed, if

$$
\eta_{t}=\tilde{Q}_{t}-\beta\left[\frac{\tilde{\Lambda}_{t+1}}{\tilde{\Lambda}_{t}}\left(\tilde{Q}_{t+1}+\tilde{D}_{t+1}\right)\right]
$$

where variables with tilda are generated using our approximate model, then the average $\eta$ should be small relative to the long run mean of the stock price, $\bar{Q}$. We find that $\bar{\eta} / \bar{Q}$ is 0.00066223 , again indicating good accuracy. ${ }^{13}$

In conclusion, we believe that our approximation method performs better than second order log perturbation (in the sense that it generates time varying risk), also well when compared to 3rd

\footnotetext{
${ }^{12}$ We may also approximate the Euler equation for bonds with a second or third order perturbation. In that case, the changes in the reported numbers are insignificant.

${ }^{13}$ The approximation passes the formal Den Haan and Marcet (1994) accuracy test in a few cases, but mostly not. However, this does not necessarily indicate a bad approximation; it is known that this test is very 'strict', in the sense that it tends to reject the hypothesis of accuracy, even when approximations are good.
} 


\begin{tabular}{|c|c|c|c|c|}
\hline & \multicolumn{4}{|c|}{25 basis points surprise increases } \\
\hline & hybrid log & 1st order log & 2nd order log & 3rd order log \\
\hline $\mathcal{M}_{q}$ & -3.3079 & -3.3077 & -3.3048 & -3.3101 \\
\hline $\mathcal{M}_{e r}$ & -3.2802 & -3.2800 & -3.2770 & -3.2823 \\
\hline & \multicolumn{4}{|c|}{100 basis points surprise increases } \\
\hline & hybrid log & 1 st order $\log$ & 2nd order log & 3rd order log \\
\hline $\mathcal{M}_{q}$ & -3.3081 & -3.3077 & -3.2958 & -3.3095 \\
\hline $\mathcal{M}_{e r}$ & -3.2803 & -3.2800 & -3.2682 & -3.2817 \\
\hline
\end{tabular}

Table 5: Stock price and excess returns multipliers, comparison to other methods.

order log perturbation. The additional advantage of our method is that it neatly separates the channels of transmission of monetary policy. Given the comparisons of our multipliers with those generated by higher order perturbations, we conjecture that the predicted size of the excess returns contribution is small not due to the fact that the approximation is poor, but rather because of the structure and features of the model at hand.

\section{Concluding Remarks}

The motivation behind our work comes from recent literature that documents the effects of unexpected monetary policy on the stock market. We ask and assess whether a basic DSGE model with New Keynesian features can account for the now well documented response of the stock market to changes in the nominal interest rate by the Central Bank, both qualitatively and quantitatively. The model we consider is the simplest possible version of a New Keynesian framework that may have the ability to explain such facts: Building on the basic New Keynesian model of Woodford (2003), first we assume that both prices and wages are sticky (the latter ingredient is required to ensure procyclical dividends) and second, we assume that households form habits (this is required to generate time varying risk aversion and equity premia, an important element of our analysis). The model is then augmented in a natural way with a financial market, which we analyze in detail in order to address our asset pricing questions. The model is parameterized in line with the business cycle literature, i.e. so that it generates commonly accepted dynamics for the main macroeconomic aggregates.

To summarize, our findings are as follows. On one hand, the model succeeds in matching the main empirical fact that we wish to capture, i.e. that an unexpected contractionary increase of the nominal interest rate of 25 basis points leads to (approximately) one percent immediate drop in the stock market; moreover, this result is very robust to simple variations and parameterizations of the model. One the other hand, when attempting to break down the impact of unexpected monetary policy on the stock price to the three relevant channels (i.e. dividends, real interest rates and ex-ante excess returns), we find that the relative contribution of real interest rates to the total impact on real stock prices is larger than what some empirical studies have documented. We attribute this to two reasons: first, to the slow mean reversion of real interest rates predicted by New Keynesian models and second to the smoothness of the endogenous consumption process of our general equilibrium setting.

What can we learn from this analysis? First, we propose a mechanism for generating this interesting asset pricing fact in the context of a general equilibrium business cycle model. Given the general difficulty in reconciling the business cycle and asset pricing literatures, we believe that 
our paper goes a rather long way in understanding the links and interactions between monetary policy and the stock market. Our analysis thus provides a platform for further research that would seek to improve our understanding of how different factors may affect these links.

Second, an interesting by-product of our analysis is that the methodology for deriving present value expressions for the asset prices preserves some of the valuable second order information that is usually lost when linearizing dynamic systems. Although the methodology described here is particular to our New Keynesian framework, we conjecture that it can be easily applied to other settings.

\section{REFERENCES}

[1] Amato, J.D. and T. Laubach, 2003. 'Estimation and control of an optimization-based model with sticky prices and wages', Journal of Economic Dynamics and Control, 27(2), 1181-1215.

[2] Amato, J.D. and T. Laubach, 1999. 'The value of interest rate smoothing: how the private sector helps the Federal Reserve', Economic Review, Federal Reserve Bank of Kansas City, $84,47-64$.

[3] Amisano, G. and O. Tristani, 2011. 'A DSGE model of the term structure with regime shifts', forthcoming in ECB Working Paper Series.

[4] Basistha, A. and A. Kurov, 2008. 'Macroeconomic cycles and the stock market's reaction to monetary policy', Journal of Banking and Finance, 32, 2606-2616.

[5] Bekaert, G., S. Cho and A. Moreno, 2010. 'New Keynesian macroeconomics and the term structure', Journal of Money, Credit and Banking 42(1), 33-62.

[6] Bernanke, B. S. and K. N. Kuttner, 2005. 'What explains the stock market's reaction to federal reserve policy?', Journal of Finance 60(3), 1221-1256.

[7] Bernanke, B. S. and I. Mihov, 1998. 'Measuring monetary policy', Quarterly Journal of Economics, 113(3), 869-902.

[8] Bhamra, H.S., A. J. Fisher and L. A. Kuehn, 2011. 'Monetary policy and corporate default', Journal of Monetary Economics, 58(5), 480-494.

[9] Bjørnland, H.C. and K. Leitemo, 2009. 'Identifying the interdependence between US monetary policy and the stock market', Journal of Monetary Economics, 56(2), 275-282.

[10] Blanchard, O.J., 1981. 'Output, the stock market and interest rates', American Economic Review, 91, 132-143.

[11] Bohl, M.T., P.L. Siklos and D. Sondermann, 2008. 'European stock markets and the ECB's monetary policy surprises', International Finance, 11(2), 117-130.

[12] Boivin, J. and M. Giannoni, 2002. 'Assessing changes in the monetary transmission mechanism: A VAR approach', Economic Policy Review 8(1), 97-111.

[13] Boldrin, M., L.J. Christiano and J.D.M. Fisher, 2001. 'Habit persistence, asset returns and the business cycle', American Economic Review, 91(1), 149-166. 
[14] Carceles-Poveda, E., 2005. 'Idiosyncratic shocks and asset returns in the RBC model: an approximate analytical approach', Macroeconomic Dynamics 9, 295-320.

[15] Carceles-Poveda, E. and C. Giannitsarou, 2008. 'Asset pricing with adaptive learning', Review of Economic Dynamics 11, 629-651.

[16] Campbell, J.Y., 2003. 'Consumption-Based Asset Pricing', Handbook of the Economics of Finance, 801-887.

[17] Campbell, J.Y., 1996. 'Understanding risk and return', Journal of Political Economy, 104(2), 298-345.

[18] Campbell, J.Y. and R.J. Shiller, 1988. 'The dividend-price ratio and expectations of future dividends and discount factors', Review of Financial Studies, 1(5), 195-228.

[19] Carlstrom, C.T. and T.S. Fuerst, 2007. 'Asset prices, nominal rigidities, and monetary policy', Review of Economic Dynamics, 10, 256-275.

[20] Castelnuovo, E. and S. Nisticò, 2010. 'Stock Market Conditions and Monetary Policy in a DSGE Model for the U.S.', Journal of Economic Dynamics and Control, 34(9), 1700-1731.

[21] Christiano, L. J., 2002. Solving Dynamic Equilibrium Models by a Method of Undetermined Coefficients, Computational Economics, 20 (1), 21-55.

[22] Christiano, L. J., M. Eichenbaum and C. L. Evans, 2005. 'Nominal rigidities and the dynamic effects of a shock to monetary policy', Journal of Political Economy, 113(1), 1-45.

[23] Christiano, L. J., M. Eichenbaum and C. L. Evans, 1999. 'Monetary policy shocks: What have we learned and to what end?', in Taylor, J.B. and Woodford, M. (eds.), Handbook of Macroeconomics 1A, chap. 2, 65-148.

[24] Clarida, R., J. Gali and M. Gertler, 2000. 'Monetary policy rules and macroeconomic stability: evidence and some theory', Quarterly Journal of Economics, 115, 147-180.

[25] Cochrane, J.H. (2008), Financial markets and the real economy, in Handbook of the Equity Premium Puzzle, chapter 7, pp. 237-325, Elsevier.

[26] Collard, F. and H. Dellas, 2006. 'Dissecting the New Keynesian Model'. Mimeograph.

[27] Craine, R. and V. Martin, 2003. 'Monetary policy shocks and security market responses', Working Paper, University of California at Berkeley.

[28] Danthine, J.P. and A. Kurman, 2004. 'Fair wages in a New Keynesian model of the business cycle', Review of Economic Dynamics 7(1), 107-142.

[29] De Paoli, B., A. Scott and O. Weeken, 2010. 'Asset pricing implications of a New Keynesian model', Journal of Economic Dynamics and Control, 34 (10), 2056-2073.

[30] Den Haan, W. and A. Marcet, 1994. 'Accuracy in Simulations', Review of Economic Studies $61(1), 3-18$. 
[31] Doh, T., 2009. 'Yield curve in an estimated nonlinear macro model', The Federal Reserve Bank of Kansas City, RWP 09-04.

[32] Dynan, K.E., 1993. 'How prudent are consumers', Journal of Political Economy, 101(6), 11041113.

[33] Ehrmann, M. and M. Fratzscher, 2004. 'Takingstock: Monetary policy transmission to equity markets', Journal of Money, Credit and Banking, 36(4), 719-737.

[34] Erceg, C.J., D.W. Henderson and A.T. Levin, 2000. 'Optimal monetary policy with staggered wage and price contracts', Journal of Monetary Economics, 46(2), 281-313.

[35] Fuhrer, J.C., 2000. 'Habit formation in consumption and its implications for monetary-policy models', American Economic Review, 90(3), 367-390.

[36] Gourinchas, P.-O. and J.A. Parker, 2001. 'The empirical importance of precautionary saving', American Economic Review, 91(2), 406-412.

[37] Gürkaynak, R.S., B. Sack and E.T. Swanson, 2005. 'Do actions speak louder than words? The response of asset prices to monetary policy actions and atatements', International Journal of Central Banking, 1(1), 55-93.

[38] Hansen, L. P. and K. Singleton, 1983. 'Risk Aversion, and the Temporal Behavior of Asset Returns', The Journal of Political Economy 91 (2) 249-265.

[39] Jermann, U.J., 1998. 'Asset pricing in production economies', Journal of Monetary Economics, $41(2), 257-275$.

[40] Judd, J.P. and G. Rudebusch, 1998. 'Taylor's rule and the Fed: 1970-1997', Economic Review, Federal Reserve Bank of San Francisco, 3, 3-16.

[41] Kholodilin, K., A. Montagnoli, O. Napolitano and B. Siliverstovs, 2009. 'Assessing the impact of the ECB's monetary policy on the stock markets: A sectoral view', Economics Letters, 105, 211-213.

[42] Kozicki, S., 1999. 'How useful are Taylor rules for monetary policy?', Economic Review, Federal Reserve Bank of Kansas City, 84, 5-33.

[43] Lastrapes, W. D., 1998. 'International evidence on equity prices, interest rates and money', Journal of International Money and Finance, 17(3), 377-406.

[44] Lee, B.-S., 1992. 'Causal relations among stock returns, interest rates, real activity and inflation', Journal of Finance, 47(4), 1591-1603.

[45] Lettau, M., 2003. 'Inspecting the mechanism: The determination of asset prices in the RBC Model', Economic Journal, 113, 550-575.

[46] Lettau, M. and H. Uhlig, 2000. 'Can habit formation be reconciled with business cycle facts?', Review of Economic Dynamics, 3(1), 79-99. 
[47] Li, E. X. N. and F. Palomino, 2009. 'Monetary policy risk and the cross-section of stock returns', Mimeograph.

[48] McCallum, B.T., 2003. 'Multiple-solution indeterminacies in monetary policy analysis', Journal of Monetary Economics, 50, 1153-1175.

[49] Milani, F., 2008. 'Learning About the Interdependence Between the Macroeconomy and the Stock Market', Mimeograph.

[50] Neri, S., 2004. 'Monetary policy and stock prices: Theory and evidence', Banca d'Italia Temi di discussione No 513 .

[51] Nsticò, S. 2012. 'Monetary Policy and Stock-Price Dynamics in a DSGE Framework', Journal of Macroeconomics, 34(1), 126-146.

[52] Pastor, L. and P. Veronesi, 2012. 'Uncertainty about Government Policy and Stock Prices', Journal of Finance, forthcoming.

[53] Patelis, A.D., 1997. 'Stock return predictability and the role of monetary policy', Journal of Finance, 52(5), 1951-1971.

[54] Rabanal, P. and J. F. Rubio-Ramirez, 2005. 'Comparing New Keynesian models of the business cycle: A Bayesian approach', Journal of Monetary Economics 52(6), 1151-1166.

[55] Rapach, D.E., 2001. 'Macro shocks and real stock prices', Journal of Economics and Business, $53(1), 5-26$.

[56] Restoy, F. and P. Weil, 2011. 'Approximate equilibrium asset prices', Review of Finance, 15(1), $1-28$.

[57] Rigobon, R. and B. Sack, 2004. 'The impact of monetary policy on asset prices', Journal of Monetary Economics, 51(8), 1553-1575.

[58] Rudebusch, G.D. and E. Swanson, 2009. 'The Bond Premium in a DSGE Model with LongRun Real and Nominal Risks', Federal Reserve Bank of San Francisco Working Paper 2008-31.

[59] Rudebusch, G.D. and T. Wu, 2008. 'A macro-finance model of the term structure, monetary policy and the economy', the Economic Journal, 118, 906-926.

[60] Schmitt-Grohe, S. and Uribe, M., 2004. 'Solving dynamic general equilibrium models using a second-order approximation to the policy function', Journal of Economic Dynamics and Control, 28, 755-775.

[61] Sialm, C., 2006. 'Stochastic taxation and asset pricing in dynamic general equilibrium', Journal of Economic Dynamics and Control, 30(3), 511-540.

[62] Svensson, L.E.O., 1986. 'Sticky goods prices, flexible asset prices, monopolistic competition and monetary policy', Review of Economic Studies, 53(3), 385-405.

[63] Thorbecke, W., 1997. 'On stock market returns and monetary policy', The Journal of Finance, $52(2), 635-654$. 
[64] Wei, C., 2009. 'A quartet of asset pricing models in nominal and real economies', Journal of Economic Dynamics and Control, 33(1), 154-165.

[65] Woodford, M., 1999. 'Optimal monetary policy inertia', NBER Working Paper 7261.

[66] Woodford, M., 2003. Interest and Prices, Princeton University Press, Princeton and Oxford.

[67] Wouters, R. and F. Smets, 2003. 'An estimated dynamic stochastic general equilibrium model of the Euro area'. Journal of European Economic Association, 1(5), 1123-1175. 